\title{
Germinal Matrix-Intraventricular Hemorrhage: A Tale of Preterm Infants
}

\author{
Walufu Ivan Egesa ${ }^{D},{ }^{1}$ Simon Odoch, ${ }^{1}$ Richard Justin Odong, ${ }^{1}$ Gloria Nakalema, ${ }^{1}$ \\ Daniel Asiimwe $\left(1,{ }^{2}\right.$ Eddymond Ekuk, ${ }^{3}$ Sabinah Twesigemukama, ${ }^{1}$ \\ Munanura Turyasiima $\mathbb{D}^{1},{ }^{1}$ Rachel Kwambele Lokengama, ${ }^{1}$ William Mugowa Waibi $\oplus^{1},{ }^{1}$ \\ Said Abdirashid, ${ }^{1}$ Dickson Kajoba, ${ }^{1}$ and Patrick Kumbowi Kumbakulu ${ }^{1}$ \\ ${ }^{1}$ Department of Paediatrics and Child Health, Faculty of Clinical Medicine and Dentistry, Kampala International University, Uganda \\ ${ }^{2}$ Department of Surgery, Faculty of Clinical Medicine and Dentistry, Kampala International University, Uganda \\ ${ }^{3}$ Department of Surgery, Faculty of Medicine, Mbarara University of Science and Technology, Uganda
}

Correspondence should be addressed to Walufu Ivan Egesa; ivanwalufu@kiu.ac.ug

Received 20 December 2020; Accepted 26 February 2021; Published 16 March 2021

Academic Editor: Somashekhar Marutirao Nimbalkar

Copyright @ 2021 Walufu Ivan Egesa et al. This is an open access article distributed under the Creative Commons Attribution License, which permits unrestricted use, distribution, and reproduction in any medium, provided the original work is properly cited.

\begin{abstract}
Germinal matrix-intraventricular hemorrhage (GM-IVH) is a common intracranial complication in preterm infants, especially those born before 32 weeks of gestation and very-low-birth-weight infants. Hemorrhage originates in the fragile capillary network of the subependymal germinal matrix of the developing brain and may disrupt the ependymal lining and progress into the lateral cerebral ventricle. GM-IVH is associated with increased mortality and abnormal neurodevelopmental outcomes such as posthemorrhagic hydrocephalus, cerebral palsy, epilepsy, severe cognitive impairment, and visual and hearing impairment. Most affected neonates are asymptomatic, and thus, diagnosis is usually made using real-time transfontanellar ultrasound. The present review provides a synopsis of the pathogenesis, grading, incidence, risk factors, and diagnosis of GM-IVH in preterm neonates. We explore brief literature related to outcomes, management interventions, and pharmacological and nonpharmacological prevention strategies for GM-IVH and posthemorrhagic hydrocephalus.
\end{abstract}

\section{Introduction}

Germinal matrix-intraventricular hemorrhage (GM-IVH) remains a devastating neurological complication with considerable mortality [1] and neurodevelopmental disability [2]. Hemorrhage originates in the capillary network of the subependymal germinal matrix (GM) of the developing brain and may disrupt the ependymal lining and progress into the lateral cerebral ventricle $[3,4]$. Although significant strides in obstetrics and neonatal medicine have led to improved survival of preterm infants with lower gestational age and birth weight [5-7], we seem to have reached the nib of our ability to ensure morbidity-free survival of very-low-birth-weight (VLBW) infants in advanced care settings $[8,9]$. In the United States, for example, Fanaroff and colleagues [10] found no significant improvement in survival without neonatal and long-term morbidity among VLBW infants between 1997 and 2002.

\section{Anatomy and Pathogenesis of GM-IVH}

The GM is located in the subependyma of the ventricular walls. It gives origin to the cerebral neuroblasts and glia, is highly cellular and gelatinous, and is richly vascularized by capillaries that are poorly supported by muscle or collagen [11]. Vascularization of the GM is prominent from 7-8 weeks of gestation and persists into the beginning of the third trimester $[12,13]$. The thickness of the GM decreases after 24 weeks of gestation and almost disappears by 36-37 weeks [11]. Animal studies showed that the characteristic 
architecture of the subependymal matrix as the border zone between cerebral arteries and the collection zone of the deep cerebral veins makes it susceptible to focal hypoxic changes [13].

The pathogenesis of GM-IVH is intricate and multifactorial, but mostly attributed to the combined fragility of the primitive GM vasculature, fluctuations in cerebral blood flow (CBF) due to low mean arterial pressure, and impaired cerebral autoregulation in clinically unstable preterm neonates $[12,14,15]$ which increases the likelihood of vascular rupture, resulting in hemorrhage that may either be restricted to the GM or extends to the adjacent lateral ventricle. Hypoxia in the GM triggers upregulation and expression of growth factors VEGF and angiopoietin-2 which induce angiogenesis. This consequently leads to formation of fragile nascent vessels that lack pericytes, display immature basal lamina low in fibronectin, and have astrocyte end-feet coverage that is deficient in glial fibrillary acidic protein $[11,16]$. In addition, platelet or coagulation disorders may accentuate the hemorrhage [11]. Hemorrhagic parenchymal infarction is thought to occur when venous occlusion from a hematoma impairs perfusion in the periventricular white matter [17].

\section{Grading of GM-IVH}

Grading systems developed by Papile et al. [18] and Volpe are the most widely accepted, although several others exist [19]. Using computed tomography scan, Papile et al. [18] developed a four-grade classification of GM-IVH based on the location and severity of hemorrhage. Grade I is defined by hemorrhage that is confined to the GM, grade II by extension of hemorrhage into lateral ventricles without ventricular dilatation, grade III when ventricular hemorrhage is present in addition to ventricular dilatation, whereas grade IV is defined by the presence of parenchymal hemorrhage [18]. A similar grading system by Volpe is based on cranial ultrasound scan (CUS). Grade I refers to hemorrhage confined to the subependymal GM, and grade II as hemorrhage within the lateral ventricle without ventricular dilation and/or hemorrhage occupying less than $50 \%$ of the ventricle. Grade III hemorrhage is defined by ventricular dilation and/or hemorrhage occupying more than $50 \%$ of the ventricle, while grade IV is ventricular hemorrhage extending into the surrounding parenchyma [20]. This is illustrated in Figure 1. Mild GM-IVH refers to grade I and II hemorrhage, while severe GM-IVH is a term used to refer to grade III and IV hemorrhage [21].

\section{Incidence of GM-IVH}

The global incidence of GM-IVH among preterm infants ranges from $14.7 \%$ to $44.7 \%$ [22-25], with considerable variation across gestational age groups, neonatal intensive care units, and countries [6, 22, 25, 26]. Hefti et al. [27] examined for GM-IVH in 345 preterm neonates autopsied from 1914 to 2015 at Boston Children's Hospital in the United States of America. The incidence of GM-IVH was $4.7 \%$ before the 1960 s and increased to $50 \%$ from 1975 to 1980 following the introduction of novel positive pressure mechanical venti- lation in neonatal intensive care units (NICUs), later declining by three quarters to $12.5 \%$ in 2005 , probably as a result of improvements in ventilators, and the introduction of surfactant and corticosteroids. Based on age at onset, almost $40.6 \%$ of low-birth-weight $(<2.5 \mathrm{~kg})$ preterm neonates develop GMIVH within the first 3 days of life, $50 \%$ by day 5 , and $71.5 \%$ by day 7 [28].

\section{Risk Factors for Development and Progression of GM-IVH}

Various pre-, peri-, and postnatal factors have been implicated as independent risk factors for GM-IVH in preterm neonates. These include in vitro fertilization, absence of antenatal care, lack of maternal prenatal steroid administration, chorioamnionitis, multiple gestation, HIV exposure, fetal distress, vaginal delivery, outborn status, male gender, lower gestational age and birth weight, resuscitation at birth, delivery room intubation, anemia (low hematocrit), and blood transfusion [22, 25, 26, 28-35]. Other risk factors include clinically significant patent ductus arteriosus [36], pneumothorax $[33,37]$, higher fraction of inspired oxygen $\left(\mathrm{FiO}_{2}\right)$ during the first 24 hours, early- and late-onset sepsis [31, 33], postnatal hydrocortisone administration for hypotension, inotrope use $[29,34,38]$, respiratory distress syndrome requiring mechanical ventilation, hyponatremia, hyperglycemia [32], hypercapnia [36, 38], and severe metabolic acidosis $[34,39]$. Studies have also indicated that preterm neonates born at lower health facilities [34] and those transferred to another hospital after birth $[25,40]$ are more likely to develop GM-IVH. As such, women in preterm labor should be transported to a tertiary health facility that specializes in high-risk deliveries [38]. Equally significant are genetic risk factors such as factor V Leiden (Arg506Gln), prothrombin (G20210A) gene mutations, and methylenetetrahydrofolate reductase (MTHFR 1298A >C) polymorphism [24, 41, 42]. These risk factors are summarized in Table 1.

A proportion of preterm neonates with previously diagnosed mild GM-IVH may deteriorate to severe GM-IVH. Several risk factors including maternal lower genital tract infection, lower gestational age [43], necrotizing enterocolitis (NEC), and thrombocytopenia [44] have been documented.

\section{Clinical and Laboratory Characteristics of GM-IVH}

The majority of cases of GM-IVH are clinically silent [23, 45] and only detectable by routine brain imaging. Symptomatic neonates may manifest with convulsions, bulging fontanel, recurrent apnea, unexplained pallor, respiratory distress, and temperature instability $[46,47]$. Clinically identifiable seizures are reported more often among neonates with grade IV GM-IVH [48].

A significant reduction in the hematocrit may occur in the presence of a large hemorrhage [17]. Biomarkers for early prediction and detection of neuronal injury in neonates have gained clinical value in recent decades. This is because early diagnosis may provide a crucial window for implementation of neuroprotective interventions which may translate into 


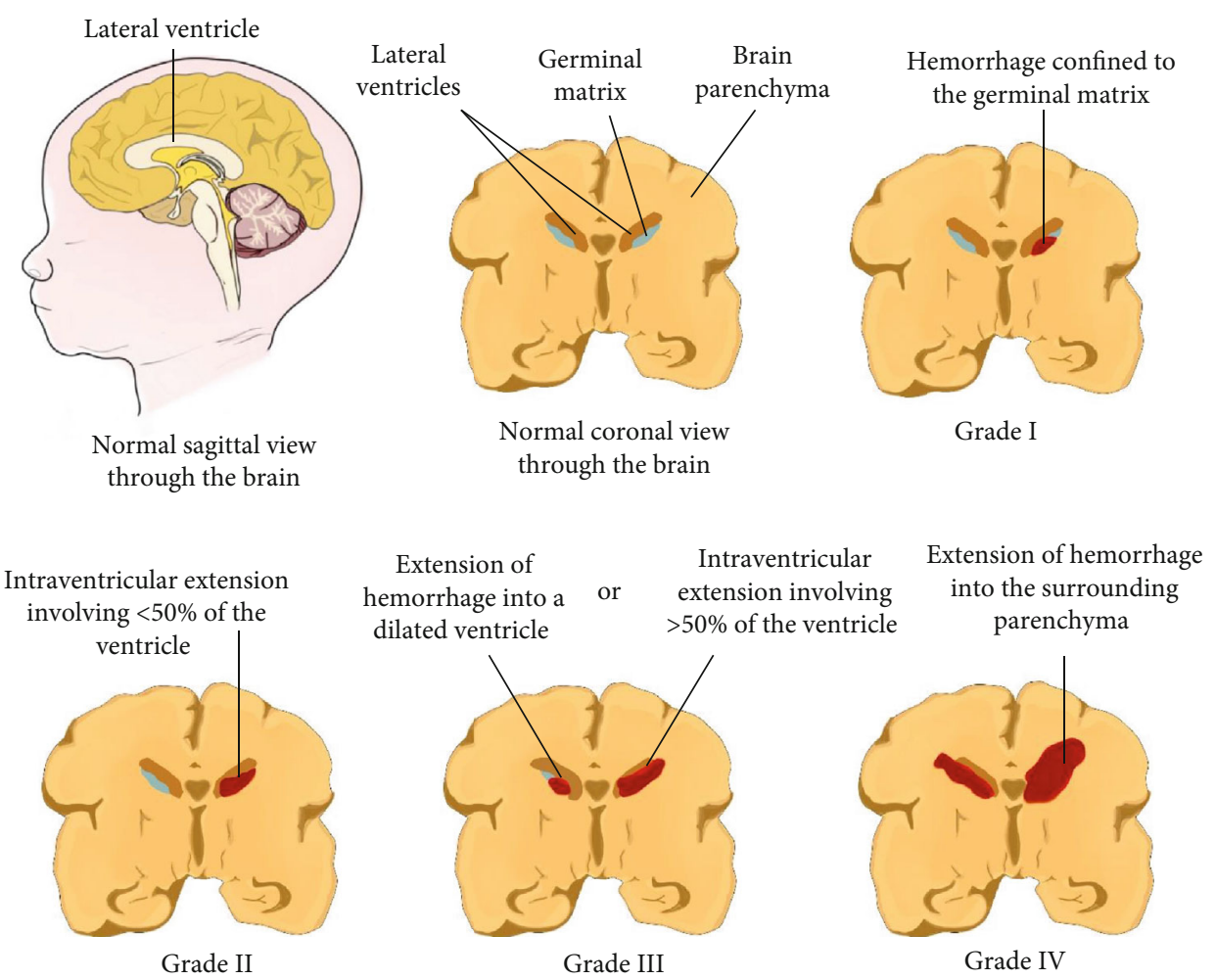

FIgURE 1: Grades of GM-IVH.

TABLE 1: Risk factors for GM-IVH in preterm infants.

(i) In vitro fertilization $[30,33]$

(ii) No antenatal care $[31,32]$

(iii) Lack of prenatal corticosteroid administration [25, 29, 31, 33, 34]

Prenatal

(iv) Chorioamnionitis $[35,36]$

(v) Multiple gestation [30]

(vi) Low gestation age [32]

(vii) Maternal HIV [28]

(viii) Inherited coagulation abnormalities [24, 41, 42]

(i) Fetal distress [22]

(ii) Vaginal delivery $[25,38]$

(iii) Extreme prematurity $[25,28,36]$

Perinatal

(iv) Very low birth weight $[28,36]$

(v) Low 5-minute APGAR score and resuscitation at birth $[25,31,36,38]$

(vi) Intubation and mechanical ventilation $[25,31,32,38]$

(vii) Male sex $[22,26]$

(i) Neonatal transfer after birth $[22,25,28,34,38,40]$

(ii) Medication (e.g., inotropes, hydrocortisone, sodium bicarbonate, normal saline boluses, and opioids) [29, 36, 38] (iii) Anemia [29]

(iv) Blood transfusion $[28,32]$

(v) Neonatal sepsis $[31,33,36]$

(vi) Patent ductus arteriosus [29, 31, 36]

Postnatal

(vii) Respiratory distress syndrome [32, 36]

(viii) Hypercapnia [36, 38]

(ix) High fraction of inspired oxygen during the first 24 hours [33]

(x) Pneumothorax [33, 37]

(xi) Hypotension [34, 38]

(xii) Hyponatremia [32]

(xiii) Hyperglycemia [32]

(xiv) Metabolic acidosis [34, 39] 
improved outcomes. Investigators have proposed several biomarkers including $\mathrm{S} 100 \beta$, activin A, adrenomedullin, erythropoietin, neuron-specific enolase, oxidative stress markers, glial fibrillary acidic protein, and creatine phosphokinase $\mathrm{BB}$ (CPK-BB). Among these metabolites, elevated $\mathrm{S} 100 \beta$ levels in the blood and urine and activin A levels in the blood are the most promising $[49,50]$.

\section{Cranial Ultrasound}

7.1. The Role of CUS. Since the late 1970s, high-resolution real-time cranial ultrasound (CUS) has been the cornerstone for diagnosis of GMH-IVH [51], with a sensitivity and specificity of $96 \%$ and $94 \%$, respectively, for detecting intracranial hemorrhage [52]. Worldwide, CUS remains the most readily available and widely used neuroimaging modality in NICUs $[53,54]$. Most importantly, CUS is portable, reliable, costeffective, noninvasive, and radiation-free, and does not require any special preparation $[53,55,56]$. However, the findings are operator-dependent, and subtle lesions may be missed [53]. The anterior fontanelle is the most commonly used site, but an acoustic window through the posterior and mastoid fontanelles can significantly augment the findings $[57,58]$. CUS can be performed at the bedside and in the incubator, within less than 5 minutes and without significant manipulation of the infant [55].

Sonographic abnormalities should be correlated on both coronal and parasagittal views, and findings on the left and right sides should be graded separately, and the location, size, and extent of the lesions are noted [59]. Interpretation of ventricular width should be done with consideration of the gestational age-specific reference ranges, as determined by Levene in 1981 [60].

7.2. When Should CUS Be Performed? The timing of screening varies depending on the protocol adopted, although consensus seems to have been reached regarding the screening of all preterm neonates born before 32 weeks of gestation and/or those with VLBW $[53,58]$. Nonetheless, most cases of GM-IVH occur during the first week of life $[23,28]$, which guides the timing of serial CUS screening. It is important to note that GM-IVH may be progressive [28], and the grade may change over time, justifying the need for CUS screening over multiple time points. In the 1980s, the initial CUS was performed during the first 3 days of life, often within 24 hours, repeated a week later among survivors, and weekly thereafter as indicated [54]. In Europe, diagnosis of GMIVH is made by performing a bedside real-time CUS, usually on day $1,3,7,14$, and 28 , although regular scanning may be indicated [59]. Recent Canadian guidelines recommend routine CUS for all neonates born at $<32$ weeks between days 4 and 7 of life or earlier depending on the clinical state of the preterm infant. Neonates born at $\geq 32$ to $<37$ weeks are similarly investigated only if additional risk factors such as complicated monochorionic twin gestation, microcephaly, need for critical care, sepsis, NEC, major surgery, and/or abnormal neurological symptoms are present. Repeat imaging is performed at 4 to 6 weeks of life for all neonates born at $<32$ weeks and for $\geq 32$ to $<37$ weeks of gestation if the first
CUS result was abnormal [53]. In 2020, the American Academy of Pediatrics [58] recommended CUS for all preterm infants born at $\leq 30$ weeks or $>30$ weeks of gestation with significant risk factors. The initial CUS should be performed within the first 7-10 days, with subsequent scans at 4-6 weeks of life and at term corrected age or prior to discharge. Serial CUS should be performed for infants with abnormal CUS findings, adjusted according to the clinical state.

\section{Magnetic Resonance Imaging}

Magnetic resonance imaging (MRI) is superior to ultrasound at detecting white matter abnormalities, hemorrhagic, and cystic lesions [61]. Although MRI is increasingly being utilized, it is not readily available, requires the neonate to be sedated, and may be unsuitable for unstable severely ill infants. Nonetheless, some institutions have demonstrated that MRIs may be performed without sedation of the neonate at term equivalent age $[62,63]$. MRI may be performed at term corrected age for infants whose CUS reveals moderate to severe abnormalities such as grade III/IV GM-IVH, posthemorrhagic ventricular dilatation (PHVD), or grade III/IV periventricular leukomalacia (PVL), when clinical risk for white matter infarction (WMI) is increased or when parental reassurance is needed $[12,53]$.

\section{Clinical Outcomes}

According to $\mathrm{Wu}$ et al. [43], $8.2 \%$ of preterm neonates $(<32$ weeks) with grade II/III GM-IVH deteriorate within 7 days to grade III/IV GM-IVH. Moreover, the mortality associated with GM-IVH remains unacceptably high, even within NICUs manned by neonatologists. At least one-fifth to onethird of preterm neonates with GM-IVH die during hospitalization $[24,64]$, with almost $86 \%$ to $100 \%$ of deaths occurring within the first postnatal week $[23,65]$. Generally, mortality increases exponentially with increasing grades [23], given that $4 \%, 10 \%, 18 \%$, and $40 \%$ of preterm neonates with grades I-IV, respectively, die during the first hospital admission [66]. Survivors are more likely to have a prolonged duration of hospital stay, which imposes a significant financial burden to the health system [66].

Recent evidence shows that any grade of hemorrhage may be associated with abnormal neurodevelopmental outcomes, although adverse outcomes have often been linked to severe GM-IVH $[2,67-70]$ and lower gestational age [6, 68]. Survivors are likely to develop neurodevelopmental problems such as PHVD [71], visual and hearing impairment, severe cognitive impairment, cerebral palsy (CP), neurodevelopmental delay, and epilepsy $[2,67,68,70,72,73]$. According to Christian et al. [66], 9\% of preterm neonates with GM-IVH develop posthemorrhagic hydrocephalus $(\mathrm{PHH})$. Among these, $1 \%, 4 \%, 25 \%$, and $28 \%$ of patients with grades I-IV hemorrhage develop $\mathrm{PHH}$, respectively. Communicating $\mathrm{PHH}$ accounts for most cases, thought to occur due to mechanisms such as impaired CSF reabsorption which accompanies obliteration of the arachnoid villi by microthrombi with subsequent inflammation and fibrosis [74]. Noncommunicating hydrocephalus is theorized to 
occur due to acute obstruction of the foramen of Monro or the aqueduct by a blood clot or due to subependymal scarring [75].

\section{Management of GM-IVH}

10.1. General Strategies. Management of GM-IVH is focused on addressing systemic issues of the neonate such as blood pressure and respiratory status, which might influence progression of hemorrhage. Screening for sequelae of GM-IVH should be performed, and necessary interventions are done, including management of hypotension, shock, anemia, and metabolic acidosis through judicious use of intravenous fluids and blood transfusion. Continuous EEG or amplitude-integrated EEG monitoring is indicated in the presence of seizures [17].

10.2. Mesenchymal Stem Cell Therapy. Animal models [76] and phase I randomized controlled trials (RCTs) involving extremely preterm infants [77] have documented the promising therapeutic potential of intraventricular transplantation of allogenic mesenchymal stem cells (MSCs) in severe GMIVH. This novel therapy is thought to attenuate brain injury following GM-IVH and prevent the development of PHH. Current evidence is weak, and thus, more human clinical trials are needed to provide a stronger body of evidence regarding the therapeutic benefits and harms of MSCs [78]. Nevertheless, a phase 2 RCT [79] to evaluate the efficacy and safety of umbilical cord blood-derived MSCs (Pneumostem $^{\circledR}$ ) in 23 to $<34$ weeks' gestation preterm neonates with severe GM-IVH is ongoing. The primary outcomes of the study are death or shunt operation up to a postmenstrual age of 40 weeks.

\section{Management of PHVD and PHH}

Due to lack of strong evidence at the moment, there are no standardised protocols for treatment of PHVD and PHH [80], and optimal timing of interventions is still contentious [81]. Nonetheless, a low threshold for intervention has been linked to lower odds of death and poor neurodevelopmental outcomes [82]. Management of PHVD generally is aimed at preventing secondary damage due to raised intracranial pressure (ICP) and avoiding the need for a permanent shunt which may be associated with complications such as blockage and infection [71]. Several therapeutic options have been studied over decades, including conservative management, diuretic therapy, repeated cerebrospinal fluid (CSF) tapping to control excessive expansion, and drainage, irrigation, and fibrinolytic therapy (DRIFT) [72, 83].

\subsection{Nonsurgical Strategies}

11.1.1. Diuretics. Available evidence has proven that medical therapy with diuretics such as furosemide and acetazolamide is inefficient, because it is associated with increased mortality and neurologic outcomes, and does not reduce the need for shunt placement $[72,84]$.

11.1.2. Repeated Tapping of CSF. A Cochrane review of three randomized controlled trials (RCTs) and a quasi-RCT found no difference between conservative management and serial tapping of CSF via lumbar puncture or ventricular tapping as regards to reduced risk of major disability, multiple disability, death, or need for permanent shunt placement [85]. Needless to say, repeated ventricular punctures inflict a new injury to the frontal lobe with each puncture and may increase infection risk [86].

\subsection{Surgical Strategies}

11.2.1. DRIFT. DRIFT involves the insertion of right frontal and left occipital catheters, with intraventricular injection of tissue plasminogen activator (e.g., urokinase) that is insufficient to produce a systemic effect $[87,88]$. After 8 hours of TPA injection, irrigation with artificial CSF is commenced at a rate of $20 \mathrm{ml} /$ hour, under ICP monitoring, with the goal of maintaining a pressure $<7 \mathrm{mmHg}$. The drainage fluid clears over about 72 hours, from a dark-colored thick fluid to straw-colored CSF [87]. The DRIFT approach is associated with secondary hemorrhage and does not reduce mortality neither does it alter the need for permanent shunt placement $[89,90]$. Contrastingly, studies have shown a reduction in severe cognitive disability among survivors at 2 years of life [90] and at 10 years of life [91]. When performed within three weeks of IVH onset in extremely-low-birth-weight (ELBW) neonates, fibrinolytic therapy followed by external ventricular drainage may significantly reduce the need for permanent shunt surgery, without increasing the risk of secondary hemorrhage and infections [88]. Despite the shortcomings, DRIFT is cost-effective [91] and remains a suitable therapy [83].

11.2.2. Shunts. Neurosurgical intervention criteria, choice, and timing of temporizing CSF diversion techniques for PHH vary across centers $[81,92]$. Children with shunts from prematurity have been observed to require one or more shunt revisions and to develop slit ventricle syndrome, loculated hydrocephalus, and shunt infections more often than children with hydrocephalus due to other etiologies $[93,94]$.

(1) Ventricular Reservoir. A ventricular reservoir (VR), also known as a ventricular access device (e.g., Ommaya reservoir and $\mathrm{McComb}$ reservoir), is a temporizing treatment for $\mathrm{PHH}$ in preterm infants $[86,93,95]$ that may even eliminate the need for a permanent shunt in some cases [96-98]. It involves the placement of a ventricular catheter into the right lateral ventricle that is then connected to a subcutaneous reservoir from which CSF is intermittently aspirated percutaneously to remove CSF and maintain a stable clinical state which includes normal increase of head circumference, soft fontanel, and CUS [86, 97]. As described by Kuo [86], aspiration of the reservoir is accomplished using a scalp needle of 25 -gauge or smaller, with the infant in the supine position. How often and how much CSF is aspirated depends on the opening and closing pressures, respectively. VR was performed as the initial procedure in 50 (54.9\%) of the 91 preterm neonates who were surgically treated for $\mathrm{PHH}$ at Children's Hospital Los Angeles between 1997 and 2012 [93]. As many as $57 \%$ of patients experience complications 
TABLE 2: Strategies for prevention of GM-IVH in preterm neonates.

\begin{tabular}{lcc}
\hline Prenatal & Perinatal & Postnatal \\
\hline & & Avoid interhospital transport \\
& Elevated midline head positioning \\
Prevent preterm birth & $\begin{array}{c}\text { Delivery at a tertiary hospital } \\
\text { Prompt delivery upon recognition } \\
\text { of fetal distress }\end{array}$ & Fluid therapy for hypotension \\
& Delayed cord clamping & Near-infrared spectroscopy monitoring of cerebral oxygenation \\
& & Prevent and treat NEC and sepsis \\
& Erythropoiesis stimulation agents \\
& (e.g., erythropoietin and darbepoetin)
\end{tabular}

such as skin breakdown, ventricular hemorrhage, CSF infection, and leak [99]. Apnea and ventriculitis have also been documented [98]. Repeated tapping from a VR has been shown not to increase the risk of reservoir infection [95]. A prospective multicenter cohort of VLBW neonates with severe GM-IVH observed no difference in infection rates between VR and ventriculosubgaleal shunts (17\% versus $14 \%, p=0.71$ ) [92].

(2) Ventriculosubgaleal Shunt. Ventriculosubgaleal shunt (VSGS) placement provides a temporary treatment of $\mathrm{PHH}$ in medically unstable infants and also averts the need for repeated tapping of CSF [100]. Through a small scalp incision near the anterior fontanelle, under local anesthesia and mild sedation, a ventricular catheter is carefully placed into the lateral ventricle and anchored to the dura. Blunt dissection is performed to create a pouch between the periosteum and galea, creating a subgaleal pouch where the outermost (proximal) end of the ventricular catheter is placed to allow for CSF drainage $[86,101,102]$. The procedure is described in a recent publication by Kuo [86] and can be safely accomplished in the NICU or the operating theatre [101, 103]. Collection of CSF in the subgaleal space can result in a cosmetically unappealing scalp swelling [104]. VSGS has been associated with recurrent meningitis, subgaleal adhesions, shunt obstruction requiring ventricular catheter revision or renewal, CSF leakage, and slippage of the catheter into or out of the ventricle $[101,102,105]$. It is estimated that $12 \%$ of patients with VSGS require a permanent ventriculoperitoneal shunt [101], which if needed is often placed when the CSF protein content decreases to $<2 \mathrm{~g} / \mathrm{l}$, with a cell count $<100$ cells/ $\mu$ l and negative CSF culture for bacteria [102].

(3) Permanent Ventriculoperitoneal and Ventriculoatrial Shunt. Permanent ventriculoperitoneal shunt (VPS) or ventriculoatrial shunt (VAS) placement is often performed after failure of the initial temporizing measures discussed earlier $[96,106]$. Of the $21 \%$ to $36 \%$ of preterm LBW neonates with GM-IVH who subsequently develop PHH [107-109], up to $18 \%$ to $39 \%$ require permanent VPS placement $[64,66$, 109]. Whitelaw and Aquilina [110] suggested VPS placement when ventricular enlargement continues at a body weight of around $2.5 \mathrm{~kg}$ and cerebrospinal fluid protein levels are below $1.5 \mathrm{~g} / \mathrm{l}$. On the other hand, complications associated with shunts are not uncommon, often leading to prolonged hospitalization. These include overdrainage, shunt blockage often requiring one or more shunt revisions or replacement, and infection $[96,106]$ predominantly caused by Staphylococcus species [105].

\section{Prevention of GM-IVH}

To protect the preterm brain from GM-IVH, a multifaceted approach addressing specific antenatal, delivery room, postnatal, and NICU factors should be implemented (Table 2) $[111,112]$. Since GM-IVH is primarily linked to increased vascular fragility and disturbance in $\mathrm{CBF}$, strategies are directed to strengthening the GM microvasculature and to stabilizing the CBF.

12.1. Prevent Preterm Birth. Measures that target prevention of preterm birth are the most important strategies for minimizing the occurrence of GM-IVH [21]. Preterm birth may be spontaneous or induced in situations such as eclampsia. Unless medically indicated, preterm birth can be delayed by evidence-based approaches such as antenatal progesterone supplementation from 16 to 24 weeks through 34 weeks of gestation in women with a current singleton pregnancy and previous spontaneous delivery, and those with a short cervical length ( $\leq 20 \mathrm{~mm}$ before 24 weeks' gestation). Other interventions such as avoidance of tobacco smoking during pregnancy, cervical cerclage for cervical incompetence, tocolytics for preterm labour, and dedicated preterm birth prevention clinics have been utilized $[113,114]$.

12.2. Prenatal Corticosteroids. The World Health Organization [115] strongly recommends prenatal corticosteroid use for all women at 24 to 34 weeks' gestation for whom preterm birth is imminent. Several studies have shown that the incidence of GM-IVH and white matter injury can be significantly reduced by the administration of a short course of prenatal corticosteroids such as betamethasone or dexamethasone $[22,31,33,38,116,117]$. This protective effect may be linked to a reduction in the incidence and severity of RDS [118] and NEC [119]. Prenatal corticosteroids have also been observed to stabilize the GM vasculature through suppression of vascular endothelial growth factor and increased transforming growth factor- $\beta$ (TGF- $\beta$ ) levels in animal studies. This results in angiogenic inhibition, trimming of neovasculature, and enhanced pericyte coverage, and consequently, a reduced propensity for hemorrhage [120].

12.3. Prenatal Magnesium Sulphate. Magnesium sulphate $\left(\mathrm{MgSO}_{4}\right)$ is widely used for the prevention and management of eclampsia. A meta-analysis of 6 RCTs and 5 cohort studies 
conducted between 1995 and 2004 provided evidence that $\mathrm{MgSO}_{4}$ administered to women at high risk of preterm labor provides significant neuroprotection against moderate to severe $\mathrm{CP}$, without causing adverse effects on the infants [121]. The World Health Organization, American College of Obstetricians and Gynecologists (ACOG), and the Society for Maternal-Fetal Medicine currently recommend the use of $\mathrm{MgSO}_{4}$ for women at risk of imminent preterm birth before 32 weeks of gestation for prevention of cerebral palsy during infancy and childhood [122, 123]. Compared to controls, $\mathrm{MgSO}_{4}$ has not been found to reduce the rates of GM-IVH [124].

12.4. Delivery at Tertiary Center and Avoidance of Interhospital Transport. Evidence from a large retrospective analysis of 67,596 VLBW preterm neonates found a correlation between interhospital transport and increased incidence and severity of GM-IVH [40], which has been linked to increased head and torso vibrations during neonatal transport [125]. A cohort study of 5,712 infants born at 24-30 weeks in the Australian and New Zealand Neonatal Network from 1995-97 found that infants transferred to another hospital after birth had 1.60 times higher odds of developing severe GM-IVH (95\% CI: 1.15 to $2.21, p<0.01$ ) [22]. Therefore, when high-risk preterm delivery is anticipated, it should be conducted in a tertiary center $[38,126]$.

12.5. Delayed Cord Clumping. Delayed cord clamping (DCC) results in a higher hematocrit [127-129], superior vena cava blood flow, right ventricle output, and right ventricular stroke volume [130], higher blood pressure and admission temperature [127], less delivery room resuscitation [128], and reduced early red blood cell transfusion [131, 132]. DCC has been shown to be beneficial in preventing GMIVH [129, 131, 132], NEC [133], and mortality [131], and can be safely implemented in singleton and monochorionic, dichorionic, and trichorionic multiple preterm gestations [134]. The optimal duration for cord clamping remains controversial. For preterm and term neonates not requiring resuscitation at birth, the American College of Obstetricians and Gynecologists, American Academy of Pediatrics, and American College of Nurse-Midwives recommend at least a 30-60-second delay to clamp the cord [135], whereas the World Health Organization strongly recommends a 60180-second delay [136].

12.6. Postnatal Indomethacin or Ibuprofen. Studies performed on beagle pups [137] suggested that postnatal intravenous administration of indomethacin may confer protection against GM-IVH by stimulating basement membrane deposition in the GM microvasculature. Although early low-dose prophylactic indomethacin in VLBW preterm infants has not been independently associated with adverse neurodevelopmental function [73, 138], evidence regarding a reduction in the incidence of GM-IVH has been controversial [139-141]. One multinational RCT of extremely-lowbirth-weight neonates found that early indomethacinprophylaxis reduces the incidence of patent ductus arteriosus and severe GM-IVH [142]. Compared to the placebo group, there was no difference in adverse neurosensory outcomes at 18 months of life. In addition, a multicenter double-blind RCT showed that administration of prophylactic ibuprofen within the first 6 hours of birth was ineffective against preventing grade II to IV GM-IVH [143]. Therefore, both indomethacin and ibuprofen are not recommended for prevention of GM-IVH, but are reserved for treatment of patent ductus arteriosus.

12.7. Midline Head Positioning and Head Tilting. Midline (neutral) head positioning is thought to optimize cerebral venous drainage through the internal jugular veins, which are the major outflow paths for cranial blood. Head rotation to either side may result in ipsilateral occlusion or obstruction of the jugular venous drainage system [144]. Nearinfrared spectroscopy (NIRS) shows that midline head position and head tilting (elevating the head of the incubator upwards by $15-30^{\circ}$ ) facilitates hydrostatic cerebral venous outflow in preterm infants $[145,146]$. Moreover, Doppler ultrasonography studies showed that occlusion of the jugular venous system by changes in head position results in large alterations in blood flow velocities in the superior sagittal sinus, increased cerebral blood volume, and ICP [145, 147, 148] which may result in GM-IVH. Head positioning and tilting has been reported to have no effect on cerebral hemodynamics and oxygenation in preterm infants [149] which contrasts the findings of other studies [148]. Recent systematic reviews and meta-analyses $[149,150]$ reported inconclusive evidence that head positioning prevents the occurrence and extension of GM-IVH. However, a single-center study [151] found that placing $<28$ weeks' gestation infants in the elevated midline head position for the first $96 \mathrm{~h}$ of life is associated with a reduced risk of grade IV GM-IVH and mortality during hospitalization.

12.8. Preventing Necrotizing Enterocolitis. NEC is associated with persistently lower cerebral tissue oxygenation [152]. There is established evidence that human breast milk [153], probiotics [154], and bovine lactoferrin supplementation $[155,156]$ reduce the risk of NEC. The precise effects of the latter on the incidence of NEC are being studied by large multicenter RCTs such as the lactoferrin infant feeding trial (LIFT) in New Zealand, Australia [157], and Canada [158].

12.9. Near-Infrared Spectroscopy Monitoring of Cerebral Oxygenation. NIRS is a real-time, continuous, and noninvasive technique similar to pulse oximetry. The device uses infrared light to penetrate living tissue and estimate brain tissue oxygenation by measuring the absorption of infrared light, according to Beer-Lambert law [159, 160]. Cerebral oxygen saturation monitoring using NIRS has become a clinically useful practice because systemic arterial oxygenation does not always reflect cerebral oxygenation [161]. In a recent multicenter study of 103 neonates born at a mean gestational age of 26 weeks and birth weight $<1250 \mathrm{~g}$, Chock and associates [162] found a clinically significant association between low cerebral oxygen saturation using NIRS in the first 96 hours of life and abnormal cranial ultrasonographic 
findings. Thus, cerebral oximetry can be used to monitor high-risk infants such that timely interventions are taken to improve cerebral oxygenation [162].

12.10. Ethamsylate. Ethamsylate is thought to promote platelet adhesion and increase capillary basement membrane stability through hyaluronic acid polymerization [163]. A Cochrane Database Systematic Review [164] of 1410 preterm infants from seven trials showed that infants $<35$ weeks of gestation with ethamsylate are significantly less likely to develop GM-IVH compared to controls. While a significant reduction in severe GM-IVH was observed (RR 0.67, 95\% CI 0.49 to 0.94 ), the review did not show a significant difference in neonatal mortality or neurodevelopmental outcome at two years between infants treated with ethamsylate and controls. Thus, routine use of ethamsylate for prevention of GM-IVH in preterm infants is not recommended.

12.11. Phenobarbitone. Earlier observations showed that phenobarbitone may dampen fluctuations in systemic blood pressure [165] and also protect the brain after hypoxiaischemia. A 2013 Cochrane review conducted by Smit et al. [166] involved 12 controlled trials with a sample size of 982 preterm infants. In this study, the effect of phenobarbitone on the incidence of GM-IVH was controversial, with three trials reporting a significant decrease and one trial reporting an increase. Meta-analysis showed that phenobarbitone does not reduce the risk of all IVH, severe IVH, PHVD, severe neurodevelopmental impairment, or in-hospital death. Secondly, there was an increased use of mechanical ventilation in the phenobarbitone-treated group [166]. Based on this strong evidence, postnatal phenobarbitone cannot be recommended for prevention of GM-IVH.

12.12. Recombinant Human Erythropoietin. Early intravenous administration of high-dose recombinant human erythropoietin (rhEpo) to very preterm infants ( $<32$ weeks) is safe and results in a significantly higher hematocrit, reticulocyte, and white blood cell counts and a lower platelet count within 7-10 days [167]. Preliminary studies by Fauchere et al. [167, 168] observed no differences between the rhEpo and placebo group with regard to the development of retinopathy of prematurity, IVH, sepsis, NEC, bronchopulmonary dysplasia, and mortality. On the other hand, studies suggest that rhEpo provides neuroprotection to ELBW and very preterm infants with IVH $[169,170]$.

12.13. Vitamin E. Vitamin E (tocopherol) is an oxidant that scavenges free radicals [163]. In 2003, Brion and colleagues [171] conducted a pooled analysis of twenty-six RCTs to evaluate the effect of Vitamin E supplementation on morbidity and mortality of preterm and LBW infants. Although vitamin $\mathrm{E}$ was found to reduce the risk of GM-IVH, it significantly increased the risk of sepsis in preterm infants. Among VLBW infants, the risk of severe retinopathy was reduced, whereas that of sepsis was increased, respectively. However, authors advised caution while interpreting the results, as data were heterogeneous and most included studies were conducted in the 1970s and 1980s, a time during which survival of smaller infants was low. As such, further research is required, before a recommendation can be made.

\section{Follow-Up of Survivors of GM-IVH}

Outpatient follow-up should be done to identify morbidities and provide appropriate guidance and treatment through comprehensive neurorehabilitation programs [102]. Given the increased risk of $\mathrm{PHH}$, head circumference should be continually monitored $[64,72]$. Children with neuropsychological deficits require special support while in school [73] with regard to writing, reading, and mathematics.

\section{Conclusion}

In recent years, considerable advances in perinatal-neonatal care have resulted in improved survival outcomes of babies born at the threshold of viability. This has been paralleled by a rising number of infants who develop complications such as GM-IVH, a multifactorial neuropathology that exclusively affects infants of $\leq 32$ weeks' gestation or those who weigh $<1500 \mathrm{~g}$ at birth. The GM is highly susceptible to hemorrhage due to the fragile capillary vasculature coupled with sudden fluctuations in CBF as a result of low mean arterial pressure and impaired cerebral autoregulatory mechanisms. In light of the high incidence and devastating long-term neurodevelopmental impairment associated with GM-IVH, perinatal-neonatal practitioners should optimally utilize the available evidence-based neuroprotective approaches to prevent the occurrence and extension of hemorrhage. More importantly, hospitals should adopt a protocolised schedule using serial real-time CUS to facilitate timely diagnosis of GM-IVH. Clinicians should be aware that temporary ventricular decompression can be achieved by VR and VSGS, although each has its advantages and disadvantages. There is no evidence to support the preference of one intervention technique over another for the temporary management of $\mathrm{PHH}$, which highlights the need for high-quality collaborative research.

\section{Abbreviations}

CBF: $\quad$ Cerebral blood flow

CSF: Cerebrospinal fluid

CUS: Cranial ultrasound scan

DRIFT: Drainage, irrigation, and fibrinolytic therapy

ELBW: Extremely low birth weight

GM: $\quad$ Germinal matrix

GM-IVH: Germinal matrix-intraventricular hemorrhage

HIV: Human immunodeficiency virus

ICP: Intracranial pressure

LBW: Low birth weight

MRI: $\quad$ Magnetic resonance imaging

MSC: $\quad$ Mesenchymal stem cells

NEC: Necrotizing enterocolitis

NICU: Neonatal intensive care unit

NIRS: Near-infrared spectroscopy

PHH: Posthemorrhagic hydrocephalus

PHVD: Posthemorrhagic ventricular dilatation

VLBW: Very low birth weight. 


\section{Conflicts of Interest}

The authors declare no competing interests.

\section{References}

[1] C. H. Pieper, J. Smith, D. Maree, and F. C. Pohl, "Is nCPAP of value in extreme preterms with no access to neonatal intensive care?," Journal of Tropical Pediatrics, vol. 49, no. 3, pp. 148-152, 2003.

[2] S. Bolisetty, A. Dhawan, M. Abdel-Latif, B. Bajuk, J. Stack, and K. Lui, "Intraventricular hemorrhage and neurodevelopmental outcomes in extreme preterm infants," Pediatrics, vol. 133, no. 1, pp. 55-62, 2014.

[3] P. Ballabh, "Intraventricular hemorrhage in premature infants: mechanism of disease," Pediatric Research, vol. 67, no. 1, pp. 1-8, 2010.

[4] J. J. Volpe, "Impaired neurodevelopmental outcome after mild germinal matrix-intraventricular hemorrhage," Pediatrics, vol. 136, no. 6, pp. 1-3, 2015.

[5] J. D. Horbar, G. J. Badger, J. H. Carpenter et al., "Trends in mortality and morbidity for very low birth weight infants, 1991-1999," Pediatrics, vol. 110, no. 1, pp. 143-151, 2002.

[6] X. Kong, F. Xu, R. Wu et al., "Neonatal mortality and morbidity among infants between 24 to 31 complete weeks: a multicenter survey in China from 2013 to 2014," BMC Pediatrics, vol. 16, no. 1, p. 174, 2016.

[7] B. J. Stoll, N. I. Hansen, E. F. Bell et al., "Neonatal outcomes of extremely preterm infants from the NICHD Neonatal Research Network," Pediatrics, vol. 126, no. 3, pp. 443-456, 2010.

[8] J. G. Anderson, R. J. Baer, J. C. Partridge et al., "Survival and major morbidity of extremely preterm infants: a populationbased study," Pediatrics, vol. 138, no. 1, article e20154434, 2016.

[9] H. Inoue, M. Ochiai, K. Yasuoka et al., "Early mortality and morbidity in infants with birth weight of 500 grams or less in Japan," Journal of Pediatrics, vol. 190, article 112e117.e3, pp. 112-117.e3, 2017.

[10] A. A. Fanaroff, B. J. Stoll, L. L. Wright et al., "NICHD Neonatal Research Network. Trends in neonatal morbidity and mortality for very low birthweight infants," American Journal of Obstetrics \& Gynecology, vol. 196, no. 2, pp. 147.e1-147.e8, 2007.

[11] P. Ballabh, "Pathogenesis and prevention of intraventricular hemorrhage," Clinics in Perinatology, vol. 41, no. 1, pp. 4767, 2014.

[12] C. Raybaud, T. Ahmad, N. Rastegar, M. Shroff, and N. M. Al, "The premature brain: developmental and lesional anatomy," Neuroradiology, vol. 55, no. S2, pp. 23-40, 2013.

[13] S. Takashima and K. Tanaka, "Microangiography and vascular permeability of the subependymal matrix in the premature infant," The Canadian Journal of Neurological Sciences., vol. 5, no. 1, pp. 45-50, 1978.

[14] P. Lin, K. Hagan, A. Fenoglio, P. E. Grant, and M. A. Franceschini, "Reduced cerebral blood flow and oxygen metabolism in extremely preterm neonates with low-grade germinal matrix- intraventricular hemorrhage," Scientific Reports, vol. 6, no. 1, article 25903, 2016.

[15] M. Tsuji, J. P. Saul, A. du Plessis et al., "Cerebral intravascular oxygenation correlates with mean arterial pressure in criti- cally ill premature infants," Pediatrics, vol. 106, no. 4, pp. 625-632, 2000.

[16] D. Yang, J. M. Baumann, Y. Y. Sun et al., "Overexpression of vascular endothelial growth factor in the germinal matrix induces neurovascular proteases and intraventricular hemorrhage," Science Translational Medicine, vol. 5, no. 193, article 193ra90, 2013.

[17] A. Whitelaw, "Core concepts: intraventricular hemorrhage," NeoReviews, vol. 12, no. 2, pp. e94-e101, 2011.

[18] L. A. Papile, J. Burstein, R. Burstein, and H. Koffler, "Incidence and evolution of subependymal and intraventricular hemorrhage: a study of infants with birth weights less than 1,500 gm," The Journal of Pediatrics, vol. 92, no. 4, pp. 529534, 1978.

[19] K. Kuban and R. L. Teele, "Rationale for grading intracranial hemorrhage in premature infants," Pediatrics, vol. 74 , no. 3 , pp. 358-363, 1984.

[20] T. E. Inder, J. M. Perlman, and J. J. Volpe, "Preterm IVH/posthemorrhagic hydrocephalus," in Volpe's neurology of the newborn, pp. 637-698, Elsevier, Philadelphia, 6th edition, 2018.

[21] J. Lim and E. Hagen, "Reducing germinal matrixintraventricular hemorrhage: perinatal and delivery room factors," NeoReviews, vol. 20, no. 8, pp. e452-e463, 2019.

[22] A. M. Heuchan, N. Evans, D. J. Henderson Smart, and J. M. Simpson, "Perinatal risk factors for major intraventricular haemorrhage in the Australian and New Zealand Neonatal Network, 1995-97," Archives of Disease in Childhood. Fetal and Neonatal Edition, vol. 86, no. 2, pp. 86F-890, 2002.

[23] H. Kadri, A. A. Mawla, and J. Kazah, "The incidence, timing, and predisposing factors of germinal matrix and intraventricular hemorrhage (GMH/IVH) in preterm neonates," Child's Nervous System, vol. 22, no. 9, pp. 1086-1090, 2006.

[24] L. A. Ramenghi, M. Fumagalli, M. Groppo et al., "Germinal matrix hemorrhage: intraventricular hemorrhage in very-low-birth-weight infants - the independent role of inherited thrombophilia," Stroke, vol. 42, no. 7, pp. 18891893, 2011.

[25] K. T. Yeo, R. Thomas, S. S. Chow et al., "Improving incidence trends of severe intraventricular haemorrhages in preterm infants <32 weeks gestation: a cohort study," Archives of Disease in Childhood - Fetal and Neonatal Edition, vol. 105, no. 2, pp. 145-150, 2020.

[26] M. A. Mohamed and H. Aly, "Male gender is associated with intraventricular hemorrhage," Pediatrics, vol. 125, no. 2, pp. e333-e339, 2010.

[27] M. M. Hefti, F. L. Trachtenberg, R. L. Haynes, C. Hassett, J. J. Volpe, and H. C. Kinney, "A century of germinal matrixintraventricular hemorrhage in autopsied premature infants: a historical account," Pediatric and Developmental Pathology, vol. 19, no. 2, pp. 108-114, 2016.

[28] T. Maduray, F. Mamdoo, and R. Masekela, "A retrospective study on the prevalence, severity and outcomes of intraventricular haemorrhage in infants with a low birth weight in a quarternary hospital in a low- to middle-income country," South African Journal of Child Health, vol. 13, no. 2, pp. 56-62, 2019.

[29] M. M. al-Mouqdad, A. Abdelrahim, A. T. Abdalgader et al., "Risk factors for intraventricular hemorrhage in premature infants in the central region of Saudi Arabia," International Journal of Pediatrics and Adolescent Medicine, 2019. 
[30] A. Bordbar and M. Farjadnia, "Maternal morbidities and occurrence of intraventricular hemorrhage in preterm infants," Journal of Pediatric Intensive Care, vol. 4, no. 3, pp. 156-161, 2015.

[31] A. Ghoor, G. Scher, and D. E. Ballot, "Prevalence of and risk factors for cranial ultrasound abnormalities in very-lowbirth-weight infants at Charlotte Maxeke Johannesburg Academic Hospital," African Journal of Child Health, vol. 11, no. 2, pp. 66-70, 2017.

[32] E. A. Guzman, J. R. D. Bertagnon, and Y. Juliano, "Frequency of peri-intraventricular hemorrhage and its associated factors in premature newborns," Einstein, vol. 8, no. 3, pp. 315-319, 2010.

[33] N. Linder, O. Haskin, O. Levit et al., "Risk factors for intraventricular hemorrhage in very low birth weight premature infants: a retrospective case-control study," Pediatrics, vol. 111, no. 5, pp. e590-e595, 2003.

[34] D. Szpecht, M. Szymankiewicz, I. Nowak, and J. Gadzinowski, "Intraventricular hemorrhage in neonates born before 32 weeks of gestation - retrospective analysis of risk factors," Child's Nervous System, vol. 32, pp. 13991404, 2016.

[35] E. Villamor-Martinez, M. Fumagalli, O. Mohammed Rahim et al., "Chorioamnionitis is a risk factor for intraventricular hemorrhage in preterm infants: a systematic review and meta-analysis," Frontiers in Physiology, vol. 9, p. 1253, 2018.

[36] I. Khanafer-Larocque, A. Soraisham, A. Stritzke et al., "Intraventricular hemorrhage: risk factors and association with patent ductus arteriosus treatment in extremely preterm neonates," Frontiers in Pediatrics, vol. 7, p. 408, 2019.

[37] A. Hill, J. M. Perlman, and J. J. Volpe, "Relationship of pneumothorax to occurrence of intraventricular hemorrhage in the premature newborn," Pediatrics, vol. 69, no. 2, pp. 144149, 1982.

[38] N. Kaksal, B. Baytan, Y. Bayram, and E. Nacarkucuk, "Risk factors for intraventricular haemorrhage in very low birth weight infants," Indian Journal of Pediatrics, vol. 69, no. 7, pp. 561-564, 2002.

[39] I. R. Goswami, A. A. Mehrem, J. Scott, M. J. Esser, and K. Mohammad, "Metabolic acidosis rather than hypo/hypercapnia in the first 72 hours of life associated with intraventricular hemorrhage in preterm neonates," The Journal of Maternal-Fetal \& Neonatal Medicine, vol. 18, pp. 1-9, 2019.

[40] M. A. Mohamed and H. Aly, "Transport of premature infants is associated with increased risk for intraventricular haemorrhage," Archives of Disease in Childhood. Fetal and Neonatal Edition, vol. 95, pp. F403-F407, 2010.

[41] J. Petaja, L. Hiltunen, and V. Fellman, "Increased risk of intraventricular hemorrhage in preterm infants with thrombophilia," Pediatric Research, vol. 49, no. 5, pp. 643-646, 2001.

[42] D. Szpecht, J. Gadzinowski, A. Seremak-Mrozikiewicz, G. Kurzawińska, K. Drews, and M. Szymankiewicz, "The role of FV 1691G >A, FII 20210G $>$ A mutations and MTHFR $677 \mathrm{C}>\mathrm{T} ; 1298 \mathrm{~A}>\mathrm{C}$ and 103G $>\mathrm{T}$ FXIII gene polymorphisms in pathogenesis of intraventricular hemorrhage in infants born before 32 weeks of gestation," Child's Nervous System, vol. 33, no. 7, pp. 1201-1208, 2017.

[43] T. Wu, Y. Wang, T. Xiong et al., "Risk factors for the deterioration of periventricular-intraventricular hemorrhage in preterm infants," Scientific Reports, vol. 10, no. 1, article 13609, 2020.
[44] H. C. Jen, J. J. Graber, J. L. Hill, S. M. Alaish, R. W. Voigt, and E. D. Strauch, "Surgical necrotizing enterocolitis and intraventricular hemorrhage in premature infants below $1000 \mathrm{~g}$," Journal of Pediatric Surgery, vol. 41, no. 8, pp. 1425-1430, 2006.

[45] J. M. Perlman and N. Rollins, "Surveillance protocol for the detection of intracranial abnormalities in premature neonates," Archives of Pediatrics \& Adolescent Medicine, vol. 154, no. 8, pp. 822-826, 2000.

[46] S. A. Adegoke, A. O. Olugbemiga, K. P. Bankole, and O. A. Tinuade, "Intraventricular hemorrhage in newborns weighing <1500 g: epidemiology and short-term clinical outcome in a resource-poor setting," Annals of Tropical Medicine and Public Health, vol. 7, no. 1, pp. 48-54, 2014.

[47] T. Ahmed, A. Baki, T. Begum, and N. Nahar, "Clinical presentation of preterm neonates with intraventricular hemorrhage: experience in a tertiary care hospital in Dhaka," BIRDEM Medical Journal, vol. 7, no. 3, pp. 194-197, 2017.

[48] V. Patil, M. Patil, S. Sarawade, S. Kumbhojkar, and K. V. Suresh, "Assessment of intraventricular haemorrhage in preterm neonates using neurosonography through anterior fontanelle," International Journal of Health Sciences and Research, vol. 7, no. 3, pp. 27-31, 2017.

[49] I. Bersani, C. Auriti, M. P. Ronchetti, G. Prencipe, D. Gazzolo, and A. Dotta, "Use of early biomarkers in neonatal brain damage and sepsis: state of the art and future perspectives," BioMed Research International, vol. 2015, Article ID 253520, 10 pages, 2015.

[50] M. Douglas-Escobar and M. D. Weiss, "Biomarkers of brain injury in the premature infant," Frontiers in Neurology, vol. 3, p. 185, 2013.

[51] K. Pape, G. Cusick, R. J. Blackwell et al., "Ultrasound detection of brain damage in preterm infants," The Lancet., vol. 313, no. 8129, pp. 1261-1264, 1979.

[52] E. E. Sauerbrei, M. Digney, P. B. Harrison, and P. L. Cooperberg, "Ultrasonic evaluation of neonatal intracranial hemorrhage and its complications," Radiology, vol. 139, no. 3, pp. 677-685, 1981.

[53] M. Guillot, V. Chau, B. Lemyre, and Canadian Paediatric Society, Fetus and Newborn Committee, "Routine imaging of the preterm neonatal brain. Canadian Pediatric Society," October 2020. Retrieved from: https://www.cps.ca/en/ documents/position/routine-imaging-of-preterm-neonatalbrain. Accessed on November 7, 2020.

[54] A. G. S. Philip, W. C. Allan, A. M. Tito, and L. R. Wheeler, "Intraventricular hemorrhage in preterm infants: declining incidence in the 1980s," Pediatrics, vol. 84, no. 5, pp. 797801, 1989.

[55] M. I. Levene, J. S. Wigglesworth, and V. Dubowitz, "Cerebral structure and intraventricular haemorrhage in the neonate: a real-time ultrasound study," Archives of Disease in Childhood, vol. 56, no. 6, pp. 416-424, 1981.

[56] A. M. H. Shehadeh and A. K. Sammak, "Neonatal cranial ultrasound: a review article," Hamdan Medical Journal, vol. 13, no. 2, pp. 66-68, 2020.

[57] F. Correa, G. Enríquez, J. Rosselló et al., "Posterior fontanelle sonography: an acoustic window into the neonatal brain," AJNR. American Journal of Neuroradiology, vol. 25, no. 7, pp. 1274-1282, 2004.

[58] I. L. Hand, R. A. Shellhaas, S. S. Milla, and COMMITTEE ON FETUS AND NEWBORN, SECTION ON NEUROLOGY, 
SECTION ON RADIOLOGY, "Routine neuroimaging of the preterm brain," Pediatrics, vol. 146, no. 5, article e2020029082, 2020.

[59] R. M. Jones, E. M. Clark, K. Broad, and E. Smit, "Outcome following preterm intraventricular haemorrhage - what to tell the parents," Paediatr Child Health (Oxford), vol. 28, no. 9, pp. 431-435, 2018.

[60] M. I. Levene, "Measurement of the growth of the lateral ventricles in preterm infants with real-time ultrasound," Archives of Disease in Childhood, vol. 56, pp. 900-904, 1981.

[61] M. Hinojosa-Rodríguez, T. Harmony, C. Carrillo-Prado et al., "Clinical neuroimaging in the preterm infant: diagnosis and prognosis," Neuroimage Clin., vol. 16, no. 16, pp. 355-368, 2017.

[62] A. M. Mathur, J. J. Neil, R. C. McKinstry, and T. E. Inder, "Transport, monitoring, and successful brain MR imaging in unsedated neonates," Pediatric Radiology, vol. 38, no. 3, pp. 260-264, 2008.

[63] V. Neubauer, E. Griesmaier, K. Baumgartner, A. Mallouhi, M. Keller, and U. Kiechl-Kohlendorfer, "Feasibility of cerebral MRI in non-sedated preterm-born infants at termequivalent age: report of a single centre," Acta Paediatrica, vol. 100, no. 12, pp. 1544-1547, 2011.

[64] V. Gilard, A. Chadie, F. Ferracci et al., "Post hemorrhagic hydrocephalus and neurodevelopmental outcomes in a context of neonatal intraventricular hemorrhage: an institutional experience in 122 preterm children," BMC Pediatrics, vol. 18, no. 1, p. 288, 2018.

[65] T. Schindler, L. Koller-smith, K. Lui, B. Bajuk, and S. Bolisetty, "Causes of death in very preterm infants cared for in neonatal intensive care units: a population-based retrospective cohort study," BMC Pediatrics, vol. 17, no. 1, p. 59, 2017.

[66] E. A. Christian, D. Jin, F. Attenello et al., "Trends in hospitalization of preterm infants with intraventricular hemorrhage and hydrocephalus in the United States, 2000-2010," Fluids and Barriers of the CNS., vol. 12, Suppl 1, p. O1, 2015.

[67] Y. Futagi, Y. Toribe, K. Ogawa, and Y. Suzuki, "Neurodevelopmental outcome in children with intraventricular hemorrhage," Pediatric Neurology, vol. 34, no. 3, pp. 219-224, 2006.

[68] K. Klebermass-Schrehof, C. Czaba, M. Olischar et al., "Impact of low-grade intraventricular hemorrhage on long-term neurodevelopmental outcome in preterm infants," Child's Nervous System, vol. 28, no. 12, pp. 2085-2092, 2012.

[69] A. Mukerji, V. Shah, and P. S. Shah, "Periventricular/intraventricular hemorrhage and neurodevelopmental outcomes: a meta-analysis," Pediatrics, vol. 136, no. 6, pp. 1132-1143, 2015.

[70] R. L. Sherlock, P. J. Anderson, and L. W. Doyle, "Victorian Infant Collaborative Study Group. Neurodevelopmental sequelae of intraventricular haemorrhage at 8 years of age in a regional cohort of ELBW/very preterm infants," Early Human Development, vol. 81, pp. 909-916, 2005.

[71] A. Whitelaw, M. Thoresen, and I. Pople, "Posthaemorrhagic ventricular dilatation," Archives of Disease in Childhood. Fetal and Neonatal Edition, vol. 86, no. 2, pp. 72F-774, 2002.

[72] C. R. Kennedy, S. Ayers, M. J. Campbell et al., "Randomized, controlled trial of acetazolamide and furosemide in posthemorrhagic ventricular dilation in infancy: follow-up at 1 year," Pediatrics, vol. 108, no. 3, pp. 597-607, 2001.
[73] T. M. Luu, L. R. Ment, K. C. Schneider, K. H. Katz, W. C. Allan, and B. R. Vohr, "Lasting effects of preterm birth and neonatal brain hemorrhage at 12 years of age," Pediatrics, vol. 123, no. 3, pp. 1037-1044, 2009.

[74] A. Hill, G. D. Shackelford, and J. J. Volpe, "A potential mechanism of pathogenesis for early posthemorrhagic hydrocephalus in the premature newborn," Pediatrics, vol. 73, no. 1, pp. 19-21, 1984.

[75] J. Strahle, H. J. L. Garton, C. O. Maher, K. M. Muraszko, R. F. Keep, and G. Xi, "Mechanisms of hydrocephalus after neonatal and adult intraventricular hemorrhage," Translational Stroke Research, vol. 3, no. S1, pp. 25-38, 2012.

[76] S. Y. Ahn, Y. S. Chang, D. K. Sung et al., "Mesenchymal stem cells prevent hydrocephalus after severe intraventricular hemorrhage," Stroke, vol. 44, no. 2, pp. 497-504, 2013.

[77] S. Y. Ahn, Y. S. Chang, S. I. Sung, and W. S. Park, "Mesenchymal stem cells for severe intraventricular hemorrhage in preterm infants: phase I dose-escalation clinical trial," Stem Cells Translational Medicine, vol. 7, no. 12, pp. 847-856, 2018.

[78] O. Romantsik, M. Bruschettini, A. Moreira, B. Thébaud, and D. Ley, "Stem cell-based interventions for the prevention and treatment of germinal matrix-intraventricular haemorrhage in preterm infants," Cochrane Database of Systematic Reviews, vol. 9, no. 9, article CD013201, 2019.

[79] ClinicalTrialsgov, "Efficacy and safety of pneumostem for IVH in premature infants (phase 2a)," NCT02890953. https://clinicaltrials.gov/ct2/show/NCT02890953.

[80] P. V. Sandoval, P. H. Rosales, D. G. Q. Hernández, E. A. C. Naranjo, and V. G. Navarro, "Intraventricular hemorrhage and posthemorrhagic hydrocephalus in preterm infants: diagnosis, classification, and treatment options," Child's Nervous System, vol. 35, pp. 917-927, 2019.

[81] A. J. Brouwer, F. Groenendaal, M. J. N. L. Benders, and L. S. De Vries, "Early and late complications of germinal matrixintraventricular haemorrhage in the preterm infant: what is new?," Neonatology, vol. 106, no. 4, pp. 296-303, 2014.

[82] M. N. Cizmeci, F. Groenendaal, K. D. Liem et al., "Randomized Controlled Early versus Late Ventricular Intervention Study in Posthemorrhagic Ventricular Dilatation: Outcome at 2 Years," The Journal of Pediatrics, vol. 226, pp. 28-35.e3, 2020.

[83] L. Mahoney, K. Luyt, D. Harding, and D. Odd, "Treatment for post-hemorrhagic ventricular dilatation: a multipletreatment meta-analysis," Frontiers in Pediatrics, vol. 8, p. 238, 2020.

[84] C. R. Kennedy, C. Kennedy, M. Campbell, and International PHVD Drug Trial Group, "International randomised controlled trial of acetazolamide and furosemide in posthaemorrhagic ventricular dilatation in infancy," Lancet, vol. 352, no. 9126, pp. 433-440, 1998.

[85] A. Whitelaw and R. Lee-Kelland, "Repeated lumbar or ventricular punctures in newborns with intraventricular haemorrhage," Cochrane Database of Systematic Reviews, vol. 4, no. 4, article CD000216, 2017.

[86] M. F. Kuo, "Surgical management of intraventricular hemorrhage and posthemorrhagic hydrocephalus in premature infants," Biomed Journal, vol. 43, no. 3, pp. 268-276, 2020.

[87] K. Aquilina, "Intraventricular haemorrhage of the newborn," Advances in clinical neuroscience \& rehabilitation : ACNR, vol. 11, no. 5, pp. 22-24, 2011. 
[88] Y. S. Park, Y. Kotani, T. K. Kim et al., "Efficacy and safety of intraventricular fibrinolytic therapy for post-intraventricular hemorrhagic hydrocephalus in extreme low birth weight infants: a preliminary clinical study," Child's Nervous System, vol. 37, no. 1, pp. 69-79, 2020.

[89] A. Whitelaw, D. Evans, M. Carter et al., "Randomized clinical trial of prevention of hydrocephalus after intraventricular hemorrhage in preterm infants: brain-washing versus tapping fluid," Pediatrics, vol. 119, no. 5, pp. e1071-e1078, 2007.

[90] A. Whitelaw, S. Jary, G. Kmita et al., "Randomized trial of drainage, irrigation and fibrinolytic therapy for premature infants with posthemorrhagic ventricular dilatation: developmental outcome at 2 years," Pediatrics, vol. 125, no. 4, pp. e852-e858, 2010.

[91] K. Luyt, S. Jary, C. Lea et al., “Ten-year follow-up of a randomised trial of drainage, irrigation and fibrinolytic therapy (DRIFT) in infants with post-haemorrhagic ventricular dilatation," Health Technology Assessment, vol. 23, no. 4, pp. 1116, 2019.

[92] J. C. Wellons 3rd, C. N. Shannon, R. Holubkov et al., "Shunting outcomes in posthemorrhagic hydrocephalus: results of a hydrocephalus clinical research network prospective cohort study," Journal of Neurosurgery. Pediatrics, vol. 20, no. 1, pp. 19-29, 2017.

[93] E. A. Christian, E. F. Melamed, E. Peck, M. D. Krieger, and J. G. McComb, "Surgical management of hydrocephalus secondary to intraventricular hemorrhage in the preterm infant," Neurosurgery: Pediatrics, vol. 17, no. 3, pp. 278284, 2016.

[94] S. Robinson, "Neonatal posthemorrhagic hydrocephalus from prematurity: pathophysiology and current treatment concepts: a review," Journal of Neurosurgery. Pediatrics, vol. 9, no. 3, pp. 242-258, 2012.

[95] K. Kormanik, J. Praca, H. J. Garton, and S. Sarkar, "Repeated tapping of ventricular reservoir in preterm infants with posthemorrhagic ventricular dilatation does not increase the risk of reservoir infection," Journal of Perinatology, vol. 30, no. 3, pp. 218-221, 2010.

[96] P. Chittiboina, H. Pasieka, A. Sonig et al., "Posthemorrhagic hydrocephalus and shunts: what are the predictors of multiple revision surgeries?," Journal of Neurosurgery: Pediatrics, vol. 11, no. 1, pp. 37-42, 2013.

[97] P. Peretta, P. Ragazzi, C. F. Carlino, P. Gaglini, and G. Cinalli, "The role of Ommaya reservoir and endoscopic third ventriculostomy in the management of post-hemorrhagic hydrocephalus of prematurity," Child's Nervous System, vol. 23, pp. 765-771, 2007.

[98] T. T. Rhodes, W. H. Edwards, R. L. Saunders et al., "External ventricular drainage for initial treatment of neonatal posthemorrhagic hydrocephalus: surgical and neurodevelopmental outcome," Pediatric Neurosurgery, vol. 13, pp. 255-262, 2004.

[99] L. Jian, S. Hang-song, L. Zheng-lang, Y. Li-sheng, W. Heng, and $\mathrm{Z} . \mathrm{Nu}$, "Implantation of Ommaya reservoir in extremely low weight premature infants with posthemorrhagic hydrocephalus: a cautious option," Child's Nervous System, vol. 28, no. 10, pp. 1687-1691, 2012.

[100] B. B. Fulmer, P. A. Grabb, W. J. Oakes, and T. B. Mapstone, "Neonatal ventriculosubgaleal shunts," Neurosurgery, vol. 47, no. 1, pp. 80-84, 2000.

[101] V. Köksal, "Ventriculosubgaleal shunt procedure and its long-term outcomes in premature infants with post- hemorrhagic hydrocephalus," Child's Nervous System, vol. 26, no. 11, pp. 1505-1515, 2010.

[102] A. Nagy, L. Bognar, I. Pataki, Z. Barta, and L. Novak, "Ventriculosubgaleal shunt in the treatment of posthemorrhagic and postinfectious hydrocephalus of premature infants," Child's Nervous System, vol. 29, no. 3, pp. 413-418, 2013.

[103] C. S. Karas, M. N. Baig, and S. W. Elton, "Ventriculosubgaleal shunts at Columbus Children's Hospital: neurosurgical implant placement in the neonatal intensive care unit," Journal of Neurosurgery, vol. 107, pp. 220-223, 2007.

[104] R. K. Kutty, S. B. Sreemathyamma, P. Korde, R. B. Prabhakar, A. Peethambaran, and G. K. Libu, "Outcome of ventriculosubgaleal shunt in the management of infectious and noninfectious hydrocephalus in pre-term infants," Journal of Pediatric Neurosciences, vol. 13, no. 3, pp. 322-328, 2018.

[105] B. K. Willis, C. R. Kumar, E. L. Wylen, and A. Nanda, "Ventriculosubgaleal shunts for posthemorrhagic hydrocephalus in premature infants," Pediatric Neurosurgery, vol. 41, no. 4, pp. 178-185, 2005.

[106] A. Reinprecht, W. Dietrich, A. Berger, G. Bavinzski, M. Weninger, and T. Czech, "Posthemorrhagic hydrocephalus in preterm infants: long-term follow-up and shuntrelated complications," Child's Nerv Syst., vol. 17, no. 11, pp. 663-669, 2001.

[107] S. Kazan, A. Güra, T. Uçar, E. Korkmaz, H. Ongun, and M. Akyuz, "Hydrocephalus after intraventricular hemorrhage in preterm and low-birth weight infants: analysis of associated risk factors for ventriculoperitoneal shunting," Surgical Neurology, vol. 64, no. S2, pp. 77-81, 2005.

[108] I. C. Lee, H. S. Lee, P. H. Su, W. J. Liao, J. M. Hu, and J. Y. Chen, "Posthemorrhagic hydrocephalus in newborns: clinical characteristics and role of ventriculoperitoneal shunts," Pediatrics and Neonatology, vol. 50, no. 1, pp. 26-32, 2009.

[109] M. Vassilyadi, Z. Tataryn, M. F. Shamji, and E. C. G. Ventureyra, "Functional outcomes among premature infants with intraventricular hemorrhage," Pediatric Neurosurgery, vol. 45, pp. 247-255, 2009.

[110] A. Whitelaw and K. Aquilina, "Management of posthaemorrhagic ventricular dilatation," Archives of Disease in Childhood - Fetal and Neonatal Edition, vol. 97, no. 3, pp. F229F233, 2012.

[111] S. C. Handley, M. Passarella, H. C. Lee, and S. A. Lorch, "Incidence trends and risk factor variation in severe intraventricular hemorrhage across a population based cohort," Journal of Pediatrics, vol. 200, pp. 24-29.e3, 2018.

[112] D. McLendon, J. Check, P. Carteaux et al., "Implementation of potentially better practices for the prevention of brain hemorrhage and ischemic brain injury in very low birth weight infants," Pediatrics, vol. 111, no. 4, pp. e497-e503, 2003.

[113] J. P. Newnham, J. E. Dickinson, R. J. Hart, C. E. Pennell, C. A. Arrese, and J. A. Keelan, "Strategies to prevent preterm birth," Frontiers in Immunology, vol. 5, p. 584, 2014.

[114] K. Rundell and B. Panchal, "Preterm labor: prevention and management," American Family Physicians, vol. 95, no. 6, pp. 366-372, 2017.

[115] World Health Organisation, "WHO recommendations on interventions to improve preterm birth outcomes," 2015. Retrieved from: https://www.who.int/reproductivehealth/ publications/maternal_perinatal_health/preterm-birthguideline/en/. 
[116] B. H. Lee, B. J. Stoll, S. A. McDonald, R. D. Higgins, and National Institute of Child Health and Human Development Neonatal Research Network, "Adverse neonatal outcomes associated with antenatal dexamethasone versus antenatal betamethasone," Pediatrics, vol. 117, no. 5, pp. 1503-1510, 2006.

[117] T. M. O'Shea and L. W. Doyle, "Perinatal glucocorticoid therapy and neurodevelopmental outcome: an epidemiologic perspective," Seminars in Neonatology, vol. 6, no. 4, pp. 293-307, 2001.

[118] H. S. Bada, "Prevention of intracranial hemorrhage," NeoReviews, vol. 1, no. 3, pp. 48e-452, 2000.

[119] T. Xiong, A. Maheshwari, J. Neu, A. EIs-aie, and M. Pammi, "An overview of systematic reviews of randomizedcontrolled trials for preventing necrotizing enterocolitis in preterm infants," Neonatology, vol. 117, pp. 46-56, 2020.

[120] G. Vinukonda, K. Dummula, S. Malik et al., "Effect of prenatal glucocorticoids on cerebral vasculature of the developing brain," Stroke, vol. 41, no. 8, pp. 1766-1773, 2010.

[121] X. Zeng, Y. Xue, Q. Tian, R. Sun, and R. An, "Effects and safety of magnesium sulfate on neuroprotection: a metaanalysis based on PRISMA guidelines," Medicine, vol. 95, no. 1, pp. 1-12, 2016.

[122] American College of Obstetricians and Gynecologists Committee on Obstetric Practice; Society for Maternal-Fetal Medicine, "Committee Opinion No. 455: Magnesium sulfate before anticipated preterm birth for neuroprotection," Obstetrics and Gynecology, vol. 115, no. 3, pp. 669-671, 2010.

[123] World Health Organization, "WHO recommendation on the use of magnesium sulfate for fetal protection from neurological complications. World Health Organization," 2015. Retrieved from: https://extranet.who.int/rhl/topics/ newborn-health/who-recommendation-use-magnesiumsulfate-fetal-protection-neurological-complications. Accessed on November 8, 2020.

[124] L. García Alonso, M. Pumarada Prieto, E. González Colmenero et al., "Prenatal treatment with magnesium sulphate: Initial clinical outcomes in pre- term infants less than 29 weeks and correlation with neonatal magnesium levels," Anales de Pediatría (Barcelona, Spain), vol. 86, no. 3, pp. 135-141, 2017.

[125] L. Blaxter, M. Yeo, D. McNally et al., "Neonatal head and torso vibration exposure during inter-hospital transfer," Journal of Engineering in Medicine, vol. 231, no. 2, pp. 99-113, 2017.

[126] M. Gleißner, G. Jorch, and S. Avenarius, "Risk factors for intraventricular hemorrhage in a birth cohort of 3721 premature infants," Journal of Perinatal Medicine, vol. 28, no. 2, pp. 104-110, 2000.

[127] N. K. Dipak, R. N. Nanavat, N. K. Kabra, A. Srinivasan, and A. Ananthan, "Effect of delayed cord clamping on hematocrit, and thermal and hemodynamic stability in preterm neonates: a randomized controlled trial," Indian Pediatrics, vol. 54, no. 2, pp. 112-115, 2017.

[128] J. W. Kaempf, M. W. Tomlinson, A. J. Kaempf et al., "Delayed umbilical cord clamping in premature neonates," Obstetrics and Gynecology, vol. 120, 2, Part 1, pp. 325-330, 2012.

[129] J. S. Mercer, B. R. Vohr, M. M. Mcgrath, J. F. Padbury, M. Wallach, and W. Oh, "Delayed cord clamping in very preterm infants reduces the incidence of intraventricular hemorrhage and late-onset sepsis: a randomized, controlled trial," Pediatrics, vol. 117, no. 4, pp. 1235-1242, 2006.
[130] R. Sommers, B. S. Stonestreet, W. Oh et al., "Hemodynamic effects of delayed cord clamping in premature infants," Pediatrics, vol. 129, no. 3, pp. e667-e672, 2012.

[131] C. H. Backes, B. K. Rivera, U. Haque et al., "Placental transfusion strategies in very preterm neonates: a systematic review and meta-analysis," Obstetrics and Gynecology, vol. 124, no. 1, pp. 47-56, 2014.

[132] A. Chiruvolu, V. N. Tolia, H. Qin et al., "Effect of delayed cord clamping on very preterm infants," American Journal of Obstetrics and Gynecology, vol. 213, no. 5, pp. 676.e1676.e7, 2015.

[133] B. D. Garg, N. S. Kabra, and A. Bansal, "Role of delayed cord clamping in prevention of necrotizing enterocolitis in preterm neonates: a systematic review," The Journal of Maternal-Fetal \& Neonatal Medicine, vol. 32, no. 1, pp. 164-172, 2019.

[134] P. Jegatheesan, E. Belogolovsky, M. Nudelman, D. Song, and B. Govindaswami, "Neonatal outcomes in preterm multiples receiving delayed cord clamping," Archives of Disease in Childhood - Fetal and Neonatal Edition, vol. 104, no. 6, pp. F575-F581, 2019.

[135] American College of Obstetricians and Gynecologists, "Delayed umbilical cord clamping after birth. Committee opinion No. 684," Obstetrics \& Gynecology, vol. 129, pp. e510, 2017.

[136] World Health Organisation, "Delayed umbilical cord clamping for improved maternal and infant health and nutrition outcomes: guideline," 2014. Retrieved from: https://www .who.int/nutrition/publications/guidelines/cord_clamping/ en/ Accessed on September 15, 2020.

[137] L. R. Ment, W. B. Stewart, T. A. Ardito, E. Huang, and J. A. Madri, "Indomethacin promotes germinal matrix microvessel maturation in the newborn beagle pup," Stroke, vol. 23, no. 8, pp. 1132-1137, 1992.

[138] L. R. Ment, B. Vohr, W. Allan et al., "Outcome of children in the indomethacin intraventricular hemorrhage prevention trial," Pediatrics, vol. 105, no. 3, pp. 485-491, 2000.

[139] the Neocosur Neonatal Network, M. J. Luque, J. L. Tapia et al., "A risk prediction model for severe intraventricular hemorrhage in very low birth weight infants and the effect of prophylactic indomethacin," Journal of Perinatology, vol. 34, no. 1, pp. 43-48, 2014.

[140] L. R. Ment, C. C. Duncan, R. A. Ehrenkranz et al., "Randomized low-dose indomethacin trial for prevention of intraventricular hemorrhage in very low birth weight neonates," The Journal of Pediatrics, vol. 112, no. 6, pp. 948-955, 1988.

[141] H. Mirza, W. Oh, A. Laptook, B. Vohr, R. Tucker, and B. S. Stonestreet, "Indomethacin prophylaxis to prevent intraventricular hemorrhage: association between incidence and timing of drug administration," Journal of Pediatrics, vol. 163, no. 3, pp. 706-710.e1, 2013.

[142] B. Schmidt, P. Davis, D. Moddemann et al., "Long-term effects of indomethacin prophylaxis in extremely-low-birthweight infants," The New England Journal of Medicine, vol. 344, no. 26, pp. 1966-1972, 2001.

[143] C. Dani, G. Bertini, M. Pezzati et al., "Prophylactic ibuprofen for the prevention of intraventricular hemorrhage among preterm infants: a multicenter, randomized study," Pediatrics, vol. 115, no. 6, pp. 1529-1535, 2005.

[144] G. H. Watson, "Effect of head rotation on jugular vein blood flow," Archives of Disease in Childhood, vol. 49, no. 3, pp. 237-239, 1974. 
[145] A. Pellicer, F. Gayá, R. Madero, J. Quero, and F. Cabañas, "Noninvasive continuous monitoring of the effects of head position on brain hemodynamics in ventilated infants," Pediatrics, vol. 109, no. 3, pp. 434-440, 2002.

[146] G. Pichler and M. van Boetzelar, "Effect of tilting on cerebral hemodynamics in preterm and term infants," Biology of the Neonate, vol. 80, no. 3, pp. 179-185, 2001.

[147] F. Cowan and M. Thoresen, "Changes in superior sagittal sinus blood velocities due to postural alterations and pressure on the head of the newborn infant," Pediatrics, vol. 75, no. 6, pp. 1038-1047, 1985.

[148] J. R. Emery and J. L. Peabody, "Head position affects intracranial pressure in newborn infants," The Journal of Pediatrics, vol. 103, no. 6, pp. 950-953, 1983.

[149] K. A. de Bijl-Marcus, A. J. Brouwer, L. S. de Vries, and G. van Wezel-Meijler, "The effect of head positioning and head tilting on the incidence of intraventricular hemorrhage in very preterm infants: a systematic review," Neonatology, vol. 111, pp. 267-279, 2017.

[150] O. Romantsik, M. G. Calevo, M. Bruschettini, and Cochrane Neonatal Group, "Head midline position for preventing the occurrence or extension of germinal matrix-intraventricular hemorrhage in preterm infants," Cochrane Database of Systematic Reviews, vol. 7, no. 7, article CD012362, 2017.

[151] M. Kochan, B. Leonardi, A. Firestine et al., "Elevated midline head positioning of extremely low birth weight infants: effects on cardiopulmonary function and the incidence of periventricular- intraventricular hemorrhage," Journal of Perinatology, vol. 39, no. 1, pp. 54-62, 2019.

[152] C. Howarth, J. Banerjee, T. Leung, S. Eaton, J. K. Morris, and N. Aladangady, "Cerebral oxygenation in preterm infants with necrotizing enterocolitis," Pediatrics, vol. 146, no. 3, article e20200337, 2020.

[153] E. A. Cristofalo, R. J. Schanler, C. L. Blanco et al., "Randomized trial of exclusive human milk versus preterm formula diets in extremely premature infants," The Journal of Pediatrics, vol. 163, no. 6, pp. 1592-1595.e1, 2013.

[154] J. Sun, G. Marwah, M. Westgarth, N. Buys, D. Ellwood, and P. H. Gray, "Effects of probiotics on necrotizing enterocolitis, sepsis, intraventricular hemorrhage, mortality, length of hospital stay, and weight gain in very preterm infants: a meta-analysis," Advances in Nutrition, vol. 8, no. 5, pp. 749-763, 2017.

[155] P. Manzoni, M. Meyer, I. Stolfi et al., "Bovine lactoferrin supplementation for prevention of necrotizing enterocolitis in very-low-birth-weight neonates: a randomized clinical trial," Early Human Development, vol. 90, Suppl 1, pp. S60-S65, 2014.

[156] M. Pammi and G. Suresh, "Enteral lactoferrin supplementation for prevention of sepsis and necrotizing enterocolitis in preterm infants," Cochrane Database of Systematic Reviews, vol. 6, article CD007137, 2017.

[157] A. Martin, A. Ghadge, P. Manzoni et al., "Protocol for the Lactoferrin Infant Feeding Trial (LIFT): a randomised trial of adding lactoferrin to the feeds of very-low birthweight babies prior to hospital discharge," BMJ Open, vol. 8, article e023044, 2018.

[158] E. V. Asztalos, K. Barrington, A. Lodha, W. Tarnow-Mordi, and A. Martin, "Lactoferrin infant feeding trial_Canada (LIFT_Canada): protocol for a randomized trial of adding lactoferrin to feeds of very-low-birth-weight preterm infants," BMC Pediatrics., vol. 20, no. 1, p. 40, 2020.
[159] H. E. Elser, D. Holditch-Davis, and D. H. Brandon, "Cerebral oxygenation monitoring: a strategy to detect IVH and PVL," Newborn and Infant Nursing Reviews, vol. 11, no. 3, pp. 153159, 2011.

[160] J. D. Tobias, "Cerebral oxygenation monitoring: nearinfrared spectroscopy," Expert Review of Medical Devices, vol. 3, pp. 235-243, 2014.

[161] L. M. Dix, F. van Bel, and P. M. Lemmers, "Monitoring cerebral oxygenation in neonates: an update," Frontiers in Pediatrics, vol. 5, p. 46, 2017.

[162] V. Y. Chock, S. H. Kwon, N. Ambalavanan et al., "Cerebral oxygenation and autoregulation in preterm infants (early NIRS study)," Journal of Pediatrics, vol. 227, pp. 94-100.e1, 2020.

[163] H. J. McCrea and R. L. Ment, "The diagnosis, management and postnatal prevention of intraventricular hemorrhage in the preterm neonate," Clinics in Perinatology, vol. 35, no. 4, pp. 777-792, 2008.

[164] R. Hunt and E. Hey, "Ethamsylate for the prevention of morbidity and mortality in preterm or very low birth weight infants," Cochrane Database of Systematic Reviews, vol. 20, no. 1, article CD004343, 2010.

[165] P. D. WIMBERLEY, H. C. LOU, H. PEDERSEN, M. HEJL, N. A. LASSEN, and B. FRIIS-HANSEN, "Hypertensive peaks in the pathogenesis of intraventricular hemorrhage in the newborn. Abolition by phenobarbitone sedation," Acta Paediatrica Scandinavica, vol. 71, no. 4, pp. 537-542, 1982.

[166] E. Smit, D. Odd, and A. Whitelaw, "Postnatal phenobarbital for the prevention of intraventricular haemorrhage in preterm infants," Cochrane Database of Systematic Reviews, vol. 8, article CD001691, 2013.

[167] J. C. Fauchère, B. M. Koller, A. Tschopp et al., "Safety of early high-dose recombinant erythropoietin for neuroprotection in very preterm infants," The Journal of Pediatrics, vol. 167, no. 1, pp. 52-57.e3, 2015.

[168] J. C. Fauchere, C. Dame, R. Vonthein et al., "An approach to using recombinant erythropoietin for neuroprotection in very preterm infants," Pediatrics, vol. 122 , no. 2 , pp. $375-$ 382, 2008.

[169] A. P. Neubauer, W. Voss, M. Wachtendorf, and T. Jungmann, "Erythropoietin improves neurodevelopmental outcome of extremely preterm infants," Annals of Neurology, vol. 67, no. 5, pp. 657-666, 2010.

[170] J. Song, H. Sun, F. Xu et al., "Recombinant human erythropoietin improves neurological outcomes in very preterm infants," Annals of Neurology, vol. 80, no. 1, pp. 24-34, 2016.

[171] L. P. Brion, E. F. Bell, and T. S. Raghuveer, "Vitamin E supplementation for prevention of morbidity and mortality in preterm infants," Cochrane Database of Systematic Reviews, vol. 4, no. 4, article CD003665, 2003. 